\title{
Predhodno poročilo o ugotovitvi parazitoida Torymus sinensis na ko- stanjevi šiškarici (Dryocosmus kuriphilus) v Sloveniji v letu 2013
}

\author{
Maja JURC $^{1 *}$, Ljubodrag Mihajlović², Barbara PIŠKUR ${ }^{3}$, Dušan Jurc ${ }^{1,3}$
}

Parazitoidna osica Torymus sinensis Kamijo, 1982 je bila uporabljena kot biotično sredstvo za zatiranje kostanjeve šiškarice (Dryocosmus kuriphilus Yasumatsu, 1951) na Japonskem (Moriya in sod., 2003), v Severni Ameriki (Rieske, 2007) in v Evropi (Quacchia in sod., 2008). V okviru leta 2008 začete pilotne raziskave parazitoidov kostanjeve šiškarice v Sloveniji prikazujemo rezultate, ki se nanašajo na $T$. sinensis. Celotni rezultati dela bodo objavljeni drugje.

\section{Material in metode}

Analizirali smo parazitiranost D. kuriphilus s tujerodno parazitoidno osico $T$. sinensis. Šiške nastale v tekočem letu in šiške iz prejšnjega leta so bile nabrane na pravem kostanju (Castanea sativa Mill.) večkrat v letih 2013 in 2014 na treh lokacijah (preglednica 1). Šiške smo po nabiranju namestili v entomološke zaboje (svetlobne eklektorje) in jih gojili na sobni temperaturi do oktobra 2015, izlegle primerke smo takrat shranili v 80odstotni etanol. Identifikacija parazitoida $T$. sinensis je bila opravljena v letu 2016 z morfološko analizo (Kamijo, 1982) in s primerjavo nukleotidnih zaporedij regij COI ter ITS2 za osebke, vzorčene v letu 2013 (Matoševič in sod., 2015; Yara, 2006; Yara, 2004).

\section{Rezultati in razprava}

Odrasli osebki T. sinensis so bili prvič ugotovljeni v kostanjevih šiškah, ki so bile nabrane na lokaciji Lipa v maju 2013, na Rožniku oktobra 2013 ter v Velikih Brusnicah septembra 2013. Za reprezentativni zaporedji za dela regije COI in ITS2 je po primerjavi z zaporedji iz zbirke GenBank z algoritmom BLAST (izvedba na dan 23. 3. 2016) prvi zadetek za COI zaporedje AB070484, ki je v $99 \%$ identičen tarčnemu zaporedju (329 bp) ter za ITS2 zaporedje AB200273, ki je $100 \%$ identičen tarčnemu zaporedju (491 bp). Zaporedji AB070484 in AB200273 pripadata vrsti T. sinensis. Primerjava zaporedja dela regije COI z zaporedji evropske avtohtone vrste T. flavipes (JQ416921, JQ416918, HM574295, HM574248) pa pokaže $89 \%$ ujemanje (329 bp). Na vseh treh vzorčenih lokacijah je bil parazitoid $T$. sinensis ugotovljen tudi v letu 2014 (slika 1, slika 2) (preglednica 1). Vsi vzorci skupaj so vsebovali 4.686 kostanjevih šišk in iz njih je izletelo 319 osebkov $T$. sinensis $(6,8 \%$ šišk je bilo parazitiranih).

Lipa leži od vseh treh lokacij vzorčenja najbližje območju v Italiji, kjer so od leta 2005 v velikem številu vnašali tega parazitoida (Quacchia in sod., 2008). Številčnost $T$. sinensis je bila na tej lokaciji izjemno velika že v vzorcu iz junija 2013, ko je bilo parazitiranih 18,5 \% šišk. Jeseni 2013 pa je bil T. sinensis ugotovljen v odvzetih vzorcih kostanjevih šišk na vseh treh lokacijah, torej se je parazitoid pojavil $\mathrm{v}$ oddaljenosti $125 \mathrm{~km}$ od Lipe.

Kostanjeva šiškarica je bila vnesena v Slovenjo leta 2004 s sadikami pravega kostanja iz province Cuneo v deželi Piemont v Italiji, ki so bile posajene v nasad na Sabotinu. Spomladi 2007 je bila ugotovljena v tem nasadu, izkoreninjenje ni bilo uspešno in začela se je hitro širiti po Sloveniji (Knapič in sod., 2010). Po naših podatkih je bila kostanjeva šiškarica ugotovljena $\mathrm{v}$ Lipi leta 2008, na Rožniku leta 2010 in v Velikih Brusnicah leta 2012. T. sinensis je bil prisoten na omenjenih lokacijah pet, tri in eno leto po napadu kostanjeve šiškarice in očitno je hitrost širjenja parazitoida mnogo hitrejša, kot je bila hitrost širjenja kostanjeve šiškarice. Morda je populacija parazitoida v Evropi že dosegla eksponentno stopnjo hitrosti širjenja, kar se je zgodilo na Japonskem približno sedem let po vnosu parazitoida (Moriya in sod., 2002). Kot sta ugotovila Colombari in Battisti (2016), je bila takšna hitrost širjenja parazitoida $\mathrm{v}$ severni Italiji najverjetneje dosežena že v enem ali dveh letih (s pomočjo vetra), saj sta v prvem letu po njegovem vnosu ugotovila največjo razdaljo širjenja parazitoida $\mathrm{v}$ enem primeru $84,1 \mathrm{~km}$ in $\mathrm{v}$ drugem primeru kar 110,5 $\mathrm{km}$. Dobljene rezultate podpirajo opažanja ob nabiranju kostanjevih šišk v začetku marca leta 2016, ko smo na vejicah pravega kostanja na lokacijah po celi Sloveniji (Ponikve, Lipa, Puče, Semič, Velike Brusnice, Majšperk, Grad, Kamnica, Homec, Smoldno, Rožnik) opazili veliko število šišk iz prejšnjih let, lanskoletne pa so bile redke in iz številnih so po štirih dnevih gojenja na sobni temperaturi pričeli množično izletavati parazitoidi T. sinensis (slika 3, slika 4). Domnevamo, da je parazitoid $T$. sinensis v letu 2015 močno zmanjšal populacijo kostanjeve šiškarice na območju cele Slovenije.

Rezultati pridobljeni v tej raziskavi se razlikujejo od rezultatov študij, ki so jih objavili Kos in sod. (2015) in Kos in Melika (2015), v katerih parazitoida T. sinensis v Sloveniji do leta 2014 niso zasledili. Tudi v sosednji italijanski deželi Furlaniji - Julijski krajini ga v letu 2014 niso zasledili (Bernardinelli in sod., 2015). V nobeni od navedenih študij ne navajajo, koliko časa so gojili šiške ali pa navajajo, da so jih gojili, dokler adulti niso izleteli. Večina vzorčenj šišk je bila opravljena v drugih časovnih obdobjih kot v naši raziskavi. Šiške smo v naši raziskavi gojili približno eno leto (vzorčenje v oktobru 2014) ali celo dve leti in pol (vzorčenje v maju 2013). Ličinke $T$. sinensis so imele v šiškah, nastalih v tekočem letu, s tako dolgim gojenjem dovolj časa za popoln razvoj in verjetno smo v nekaterih vzorcih pridobili tudi osebke s podaljšano diapavzo, o čemer poročajo Ferracini in sod. (2015).

Parazitoid $T$. sinensis je bil v Slovenijo vnesen na šestih lokacijah spomladi leta 2015. Vnosi parazitoida so 
predvideni še v nadaljnjih štirih letih (Kos in Melika, 2015; UVHVVR, 2015). Vendar rezultati, o katerih poročamo $\mathrm{v}$ tem delu, zahtevajo odgovor na pomembno vprašanje: Ali je predvideno vnašanje parazitoida $T$. sinensis v Slovenijo v letu 2016 in v naslednjih letih upravičeno oziroma smiselno? Na osnovi dobljenih rezultatov namreč ugotavljamo, da vnašanje že doslej ni bilo upravičeno ter tudi v prihodnje ni smiselno, saj je bil parazitoid $T$. sinensis splošno razširjen na raziskovanem območju že v letih 2013 in 2014, v letu 2015 pa je bil po našem mnenju že izražen njegov močan redukcijski vpliv na populacijo D. kuriphilus na območju cele Slovenije.

\section{Zahvala}

Delo je bilo opravljeno v okviru raziskovalnih programov P4-0059 (M.J.), P4-0107 (B.P., D.J.) in v prostem času (L.M.)

\section{Viri}

Bernardinelli I., Bessega D., Governatori G., Frausin C., Zandigiacomo P. 2015. Il cinipide del castagno, Dryocosmus kuriphilus, e i suoi antagonisti naturali in Friuli Venezia Giulia. Notiziario ERSA 2: $12-15$

Colombari F., Battisti A. 2016. Spread of the introduced biocontrol agent Torymus sinensis in north-eastern Italy: dispersal through active flight or assisted by wind? BioControl 61:127-139

Ferracini C., Gonella E., Ferrari E., Saladini M.A., Picciau L., Tota F., Pontini M., Alma A. 2015. Novel insight in the life cycle of Torymus sinensis, biocontrol agent of the chestnut gall wasp. BioControl 60:169-177

Kamijo K. 1982.Two new species of Torymus (Hymenoptera, Torymidae) reared from Dryocosmus kuriphilus (Hymenoptera, Cynipidae) in China and Korea. Kontyû 50, 4: 505-510

Knapič V., Seljak G., Kolšek M. 2010. Experience with Dryocosmus kuriphilus Yasumatsu eradication measures in Slovenia. EPPO Bull/Bull OEPP 40, 2:169-175

Kos K., Kriston E., Melika G. 2015. Invasive chestnut gall wasp Dryocosmus kuriphilus (Hymenoptera: Cynipidae), its native parasitoid community and association with oak gall wasps in Slovenia. European Journal of Entomology, 112, 4: 698-704
Kos K., Melika G. 2015. Kostanjeva šiškarica - kakšni so obeti za reševanje problematike v Sloveniji? Zbornik predavanj in referatov 12. slovenskega posvetovanje o varstvu rastlin $\mathrm{z}$ mednarodno udeležbo, Ptuj, 3.-4. marec 2015. Trdan S. (ur.). Ljubljana, Društvo za varstvo rastlin Slovenije: 248-253

Matošević D., Lacković N., Melika G., Kor K., Franić I., Kriston E., Bozso M., Seljak G., Rot M. 2015. Biological control of invasive Dryocosmus kuriphilus with introduced parasitoid Torymus sinensis in Croatia, Slovenia and Hungary. Periodicum Biologorum, 117: 471-477

Moriya S., Shiga M., Adachi I. 2003. Classical biological control of the chestnut gall wasp in Japan. V: Van.Driesche RG (ur.) Proceedings of the 1st international symposium on biological control of arthropods. USDA Forest Service, Washington: 407-415

Quacchia A., Moriya S., Bosio G., Scapin I., Alma A. 2008. Rearing, release and settlement prospect in Italy of Torymus sinensis, the biological control agent of the chestnut gall wasp Dryocosmus kuriphilus. BioControl 53:829-839

Rieske L.K. 2007. Success of an exotic gallmaker, Dryocosmus kuriphilus, on chestnut in the USA: a historical account. EPPO Bull/Bull OEPP 37, 1:172-174

UVHVVR, 2015. Novica. Izpust parazitske osice za zatiranje kostanjeve šiškarice (22. 4. 2015), http://www.uvhvvr.gov.si/nc/si/medijsko_sredisce/novica/article/1328/5809/ (14. 3. 2016)

Yara K. 2004. Relationship between the introduced and indigenous parasitoids Torymus sinensis and T. beneficus (Hymenoptera: Torymidae) as inferred from mt-DNA (COI) sequences. Applied Entomology and Zoology, 39: 427-433

Yara K. 2006. Identification of Torymus sinensis and T. beneficus (Hymenoptera: Torymidae), introduced and indigenous parasitoids of the chestnut gall wasp Dryocosmus kuriphilus (Hymenoptera: Cynipidae), using the ribosomal ITS2 region. Biological Control, 36: $15-21$

1Biotehniška fakulteta, Oddelek za gozdarstvo in obnovljive gozdne vire, Večna pot 83, 1000 Ljubljana, Slovenija; ${ }^{2}$ Šumarski fakultet, Kneza Višeslava 1, 11000 Beograd, Srbija; ${ }^{3}$ Gozdarski inštitut Slovenije, Oddelek za varstvo gozdov, Večna pot 2, 1000 Ljubljana, Slovenija

*maja.jurc@bf.uni-lj.si

Preglednica 1: Lokacije vzorčenja šišk, datumi nabiranja, število izleglih $T$. sinensis in število analiziranih šišk

\begin{tabular}{|c|c|c|c|c|}
\hline \multirow[t]{2}{*}{ Lokacija } & \multirow[t]{2}{*}{$\begin{array}{l}\text { Datum na- } \\
\text { biranja }\end{array}$} & \multicolumn{2}{|c|}{$\begin{array}{c}\text { Število odraslih osebkov } \\
T \text {. sinensis }\end{array}$} & \multirow[t]{2}{*}{$\begin{array}{c}\text { Ševilo šišk D. } \\
\text { kuriphilus }\end{array}$} \\
\hline & & samice ? & samci ơ & \\
\hline \multirow{5}{*}{$\begin{array}{l}\text { Lipa na Krasu } \\
\text { GKX = 398.618 m } \\
\text { GKY = 78.969 m }\end{array}$} & 18. 5. 2013 & 9 & 6 & 346 \\
\hline & 24. 6. 2013 & 124 & 95 & 1.186 \\
\hline & 1. 8.2014 & 3 & 0 & 529 \\
\hline & 9. 9.2014 & 14 & 2 & 298 \\
\hline & 23. 10. 2014 & 9 & 13 & 373 \\
\hline \multirow{3}{*}{$\begin{array}{l}\text { Rožnik v Ljubljani } \\
\text { GKX = 460.061 m } \\
\text { GKY = } 101.088 \mathrm{~m}\end{array}$} & 1. 10. 2013 & 8 & 6 & 557 \\
\hline & 9. 7. 2014 & 1 & 0 & 353 \\
\hline & 10. 10. 2014 & 1 & 0 & 123 \\
\hline \multirow{3}{*}{$\begin{array}{l}\text { Velike Brusnice } \\
\text { GKX = 520.249 m } \\
\text { GKY }=72.458 \mathrm{~m}\end{array}$} & 24. 9. 2013 & 4 & 5 & 230 \\
\hline & 15. 7. 2014 & 5 & 10 & 145 \\
\hline & 12. 10. 2014 & 2 & 2 & 546 \\
\hline SKUPAJ & & 180 & 139 & 4.686 \\
\hline
\end{tabular}




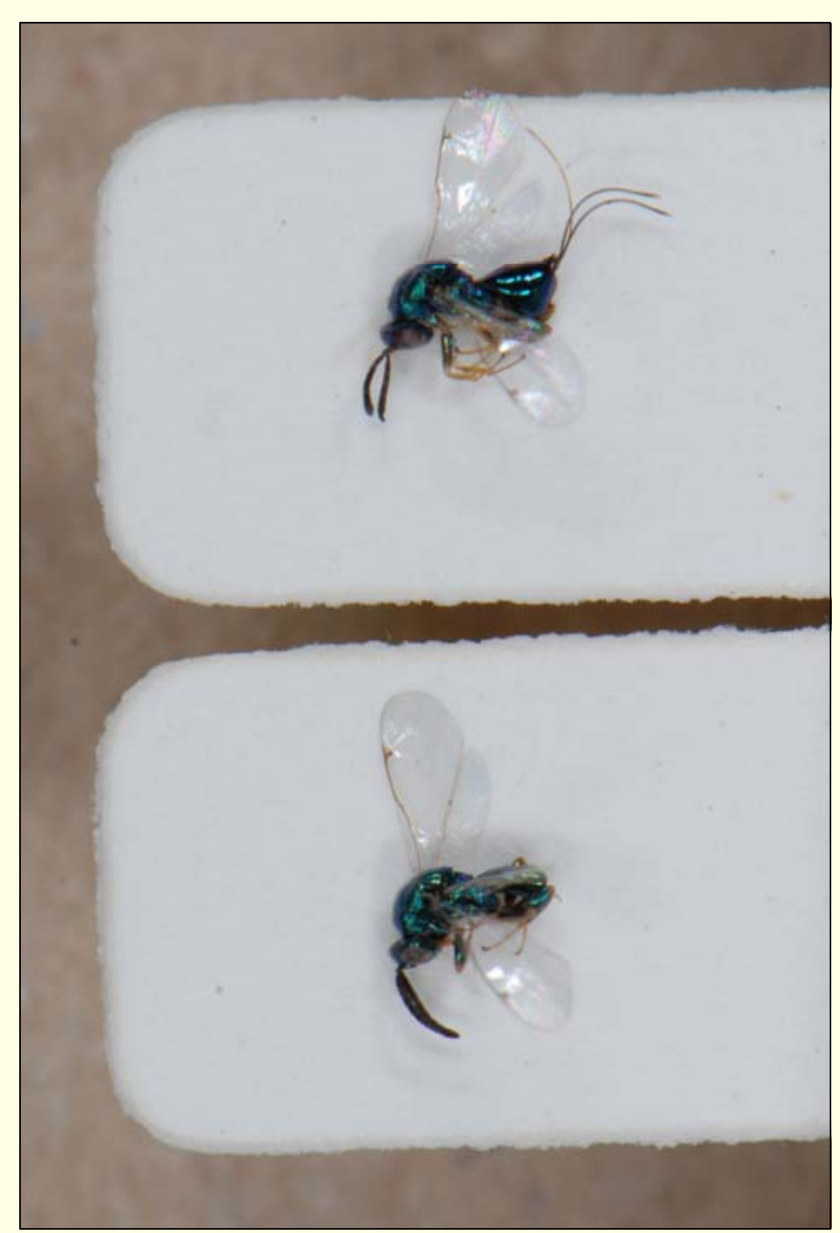

Slika 1: Preparirana primerka T. sinensis v zbirki Oddelka za gozdarstvo in obnovljive gozdne vire - entomologija, Lipa, 23. 10. 2014 (Foto D. Jurc)

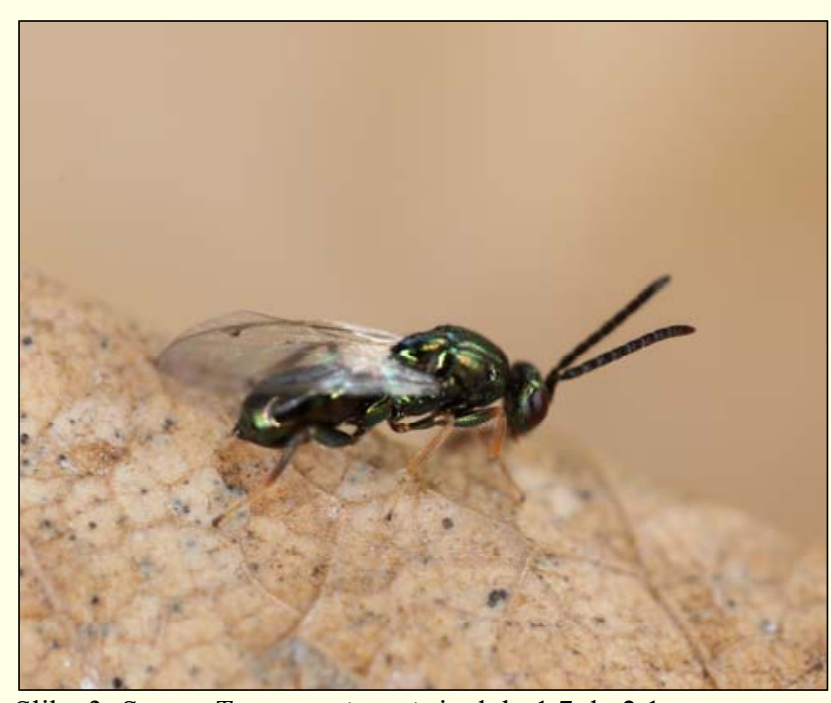

Slika 3: Samec Torymus sinensis je dolg 1.7 do $2.1 \mathrm{~mm}$, marec 2016 (Foto D. Jurc)

\section{Torymus}

sinensis Kamijo, 1982.

Det. Lj. Mihajlović, 2016.

\section{Ex. Dryocosmus \\ kuriphilus na \\ Castanea sativa}

\section{SLOV. Lipa \\ 23. X 2014. Gajeno \\ Leg. Maja Jurc}

Slika 2: Podatki, ki spremljajo vzorce v zbirki (Foto D. Jurc)

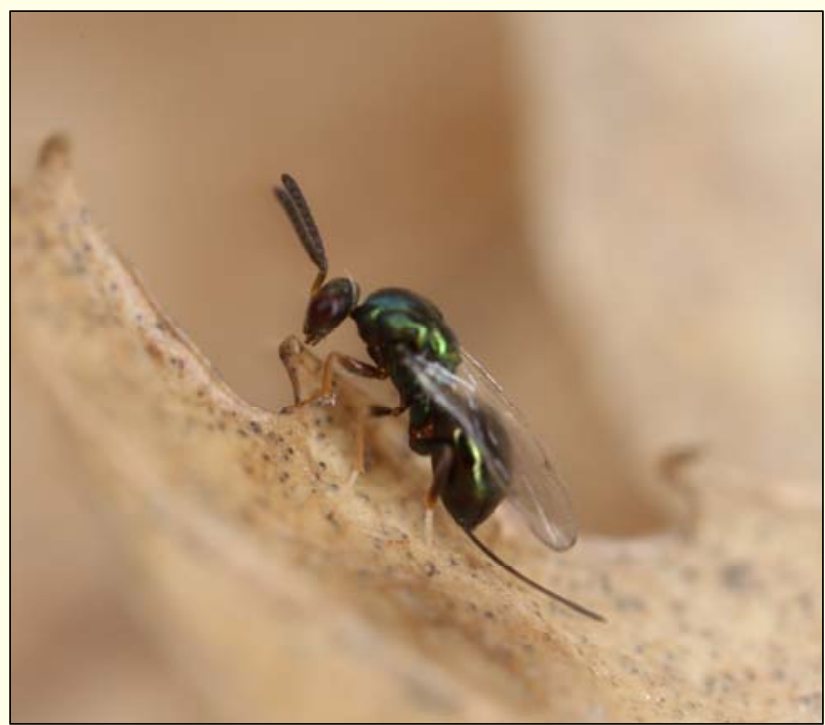

Slika 4: Samica Torymus sinensis je dolga 1.9 do $2.7 \mathrm{~mm}$, marec 2016 (Foto D. Jurc) 